\title{
BIM technology and environment management conditions
}

\author{
Anastasiia Slavina ${ }^{1, *}$, Aleksej Bychkov ${ }^{1}$, Aleksandr Komarov $^{1}$, Anton Belyaev ${ }^{1}$ \\ ${ }^{1}$ Moscow State University of Civil Engineering, Yaroslavskoye shosse, 26, 129337, Moscow, Russia
}

\begin{abstract}
The article looks into virtual units of construction design companies. Challenges in virtual organization of construction design are discussed. Modern society is characterized by transition to informational model of organization. Also, we can talk about environmental engineering, that is, to improve the quality of information environment. New forms of organization can be classified according to such characteristics as scope and nature of the activity, type of ownership, legal status, and size. These forms, along with the virtual organization, include financial and industrial groups, business unions, and clusters. It is accepted to highlight main advantages of virtual organizations in the free choice of high-class resources while reducing time costs.
\end{abstract}

\section{Introduction}

Virtual organization can be attributed to "a team of people built on division of labor" model, which is based on the theory of human relationships and behavioral sciences. Human resource is considered the most important factor, and the elements of the model are employees' motivation, their loyalty, development of communications, everything that supports relationships inside organization (Fig. 1) [1].

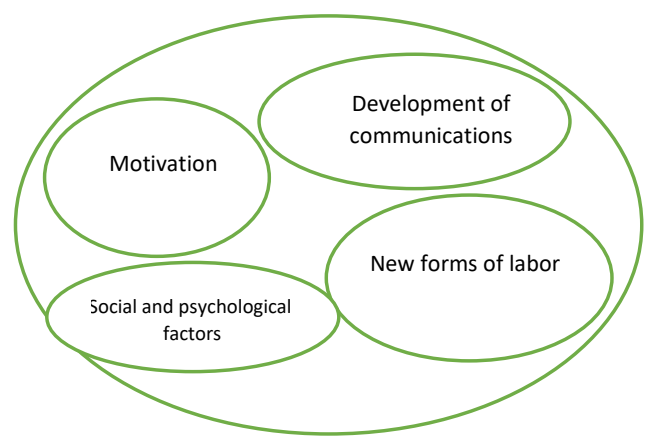

Fig. 1. Model of new organizational forms.

\footnotetext{
*Corresponding author: SlavinaAY@mgsu.ru
} 


\section{Methods}

Novelty of virtual organization can be seen at several levels, as shown in Fig. 2. At the strategic level, there is an acceleration of processes from search for ideas to the final implementation and transition to the next idea. In this case, virtual organization forms the needs of service users, which is dictated by the dynamic structure and rapid response to changing conditions. There is a transition from an attempt to strengthen weaknesses to the initial development of strengths. Structural level ensures equal cooperation of all elements of the system, considering specifics of the project. Relationships are built on the organizational level, where teamwork is an important component. Technological level is responsible for effective development of business processes, it allows to improve in real time processes, happening in the organization $[2,3]$.

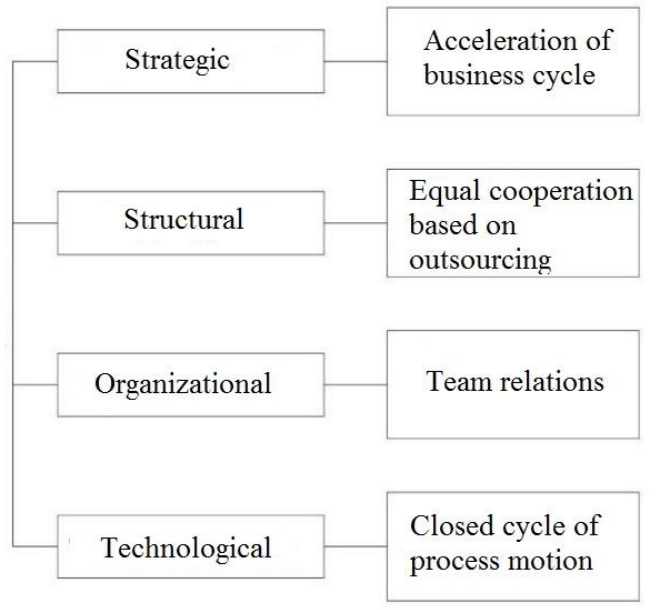

Fig. 2. Novelty of virtual organization.

During creation and further operation of virtual structures in the organization, according to the analysis of scientific literature, consequences may arise for each participant, such as:

- employment procedure;

- legal conformity of employment and taxation;

- task distribution among project participants;

- payment for virtual work;

- filing of patents and products of intellectual activity;

- financing of research;

- scope of authority and the admissibility of interference in the activities of participants by the main organization;

- remote communication between participants;

- reporting of each participant and the whole project group;

- legal relations related to the employment of foreign nationals $[4,5,6]$.

Competent use of information and communication technologies, training of HR manager about specifics of work and to be ready to adjust to new conditions - this will allow to minimize risks, connected to the virtual organization and to turn cons into pros, and there are quite a lot.

Business community has diverse forms of virtualization of activities, most often they cover performance of narrow tasks and serve to optimize the organization of labor. Thus, the concept of "virtual office" is found as often as the concept of virtual organization. 
Virtual office is provided commercially by many companies, for example 1Bitcloud, Wilstream, Corpsoft24, Lores Consulting, Softline, Softolet etc. Renting of a virtual server allows you to reduce the cost of building your own IT-infrastructure, as well as the purchase and maintenance of server equipment. This service is often used by small companies that are gaining momentum in business, who have remote offices and freelancers. Comparative analysis of virtual organization and virtual office is given in table 1 .

Table 1. Comparative analysis of virtual organization and virtual office.

\begin{tabular}{|c|c|c|}
\hline Criteria & Virtual organization & Virtual office \\
\hline Definition & $\begin{array}{l}\text { An association whose members } \\
\text { voluntarily entered professional } \\
\text { relationship in order to perform } \\
\text { defined tasks and connected to each } \\
\text { other via information networks. }\end{array}$ & $\begin{array}{l}\text { Shared office services, which often } \\
\text { include organization's business } \\
\text { address, phone number, call service, } \\
\text { web hosting and room rental. }\end{array}$ \\
\hline Benefits & $\begin{array}{l}\text { - very high flexibility and response; } \\
\text { - reduced rental and overhead } \\
\text { costs; } \\
\text { - internal coordination is done using } \\
\text { information technologies; } \\
\text { - a culture of mutual trust ensures } \\
\text { realization of activities in several } \\
\text { projects }\end{array}$ & $\begin{array}{l}\text { - } \text { quick setup of the necessary tools; } \\
\text { - } \quad \text { reduction of operational support } \\
\text { costs; } \\
\text { - lower operating costs; } \\
\text { - } \quad \text { customer data protection; } \\
\text { - use of automated control } \\
\text { programs. }\end{array}$ \\
\hline Disadvantages & $\begin{array}{l}\text { - limited control over employee } \\
\text { activities; } \\
\text { - limited control; } \\
\text { - communication difficulties, } \\
\text { potential misunderstanding; } \\
\text { - excessive dependence on staff. }\end{array}$ & $\begin{array}{l}\text { - lack of interest in the } \\
\text { development of main organization; } \\
\text { - do not work in CAD conditions; } \\
\text { - easy customer change; } \\
\text { - performance of narrow tasks } \\
\text { only; } \\
\text { - allowability to have no } \\
\text { connection; } \\
\text { - information pilfering risk. }\end{array}$ \\
\hline $\begin{array}{l}\text { Operation } \\
\text { features }\end{array}$ & $\begin{array}{l}\text { Absence of "real" organization } \\
\text { attributes such as vertical integration, } \\
\text { central office, hierarchy. }\end{array}$ & $\begin{array}{l}\text { Suggests presence of a common cloud } \\
\text { environment in which all employees } \\
\text { operate. }\end{array}$ \\
\hline $\begin{array}{l}\text { Input } \\
\text { components }\end{array}$ & $\begin{array}{l}\text { 1. Database; } \\
\text { 2. Computer, printer, phone; } \\
\text { 3. Database of projects; } \\
\text { 4. Workstations, service; } \\
\text { 5. Hardware; } \\
\text { 6. Cloud technology; } \\
\text { 7. ACS, CAD. }\end{array}$ & $\begin{array}{l}\text { 1. Multi-line phone number; } \\
\text { 2. Virtual ip-automatic telephone } \\
\text { station, capable to transfer calls to the } \\
\text { landline; } \\
\text { 3. Mobile and skype numbers. } \\
\text { 4. Mailing address to which } \\
\text { correspondence can be sent. }\end{array}$ \\
\hline
\end{tabular}

Based on the comparative analysis, it can be concluded that, considering specifics of the construction sphere, virtual organization will be more effective in its application. Virtual office services are effective when solving general work process tasks, but without any participation in construction process.

\section{Results}

Virtual structures have following key organizational parameters:

- a unified goal: shared view of values and goals. Shared view of the end result in conditions of maintaining synchrony of operations and directivity; 
- independence of team members: each member, regardless of him being individual businessman or company representative, can continue to support his independent existence alongside with getting share of the profits;

- voluntary interconnection, expressed in the voluntary joining of partnership efforts;

- multiple leaders: each person or group in the business system, based on the Network, has special uniqueness to conduct activity at any point of the process. With more than one leader, the system as a whole has greater flexibility;

- multi-level: business systems of the network operate at various levels, i.e. cooperation can be done simultaneously between organizations, departments, and population [7].

Virtualization space of enterprises can be divided into three main categories - market, reality and organizational forms (fig 3.) [8,9].

\begin{tabular}{|l|l|}
\hline $\begin{array}{l}\text { Virtual market } \\
\text { Goods and services }\end{array}$ & $\begin{array}{l}\text { Virtual reality } \\
\text { display and imitation of objects }\end{array}$ \\
\hline $\begin{array}{l}\text { Virtual organizational forms - joining into shared network of } \\
\text { individual employees via modern information and } \\
\text { communication technologies }\end{array}$ \\
\hline
\end{tabular}

Fig. 3. Virtualization space of enterprises.

Effectiveness of any organizational structure is influenced by three factors that determine a high level of production efficiency. These are relationships that occur between participants during realization of work processes, management policies and management methods used by them, as well as functions and authority of workers at different levels. Despite common factors, virtual form of the organization has its differences from traditional structures. (Fig. 4.) $[10,11]$.

Main differences between traditional and virtual

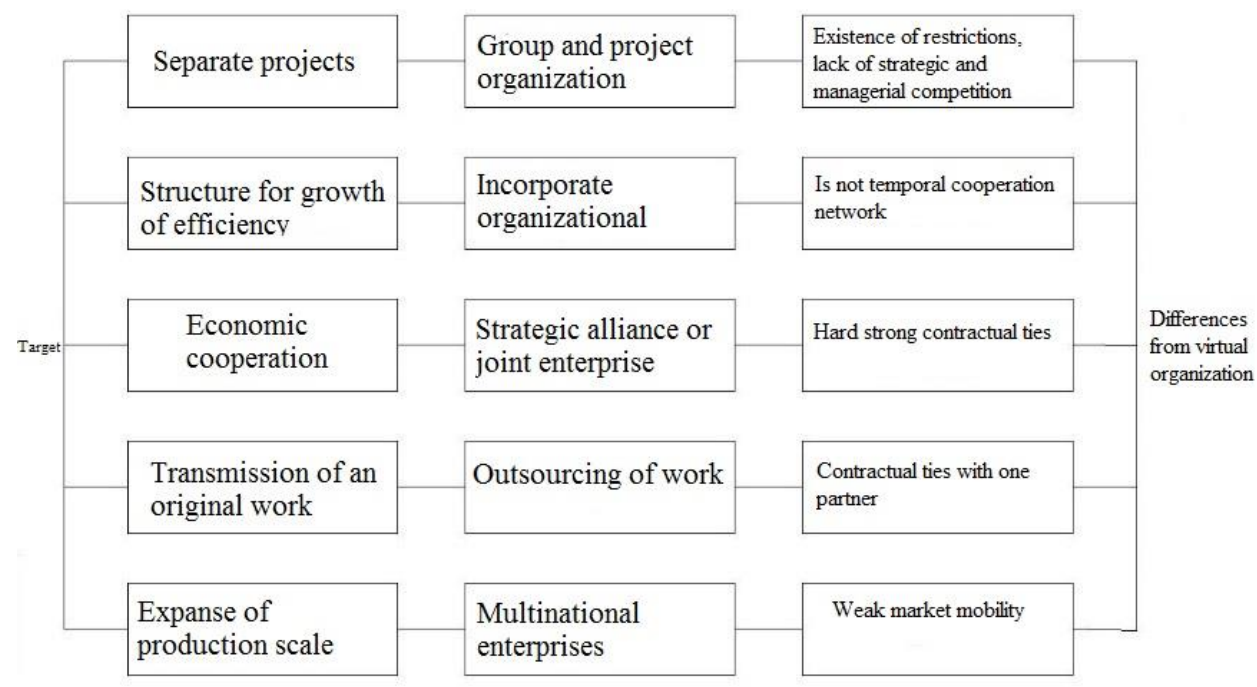

Fig. 4. The main differences between traditional and virtual infrastructures. 
This classification is designed to define the framework of a virtual organization and find its place in the design market, while combining advantages of each form.

The key concept of virtual organizations is the concept of a multi-user database. It should contain all the necessary information for computer support of the project life cycle and be available online to all team members. CALS Standards (Russian Standard) cover whole range of user needs, providing a unified view of the text, graphics, information structures and project data, support and production, including sound, video, multimedia tools, transfer and storage of data, documentation and many more

CALS technologies allow effectively, in unified manner, solve quality assurance problems of produced product, since electronic description of development processes, production etc. fully comply with international standards ISO-9000 [7].

Ideal foundation to resolve set task is to use integrated model of the project and its lifecycle, which describes object that fully, that it can be presented as single source of information for any process realized during lifecycle. The virtual structure should be based on the ideology of the integrated Internet environment $[12,13,14,15]$.

\section{Discussion}

At this stage of virtual structures research, to be able to get the first recommendations for use, we have proposed a structure that is initially built on the basis of a real-life enterprise with a traditional structure. This allows minimizing the risks and costs associated with finding an office and equipment, recruiting and marketing. An important parameter is database of projects that a real organization has, the work on which is proposed to be allocated to the responsibility of the virtual unit $[16,18,18]$.

Organizational structure of an organization may consist of several elements, each of which describes a specific relationship. The main real organization, on the basis of which the unit will be selected for the implementation of the virtual structure, has direct impact on the organization of work processes, since all other departments operate in the traditional form. The coordinating body is placed separately, it can be, both inside the virtual unit and outside it. Interaction with the structures responsible for HR work, are designed to do the drafting of employment contracts, wages, etc. These structures are located inside the main organization. Information networks are supported by consolidating efforts of the IT department of the main organization, which provides full support for the workflow in virtuality. Resolution of issues with customers is done by means of an administrative resource, taking into account interests of the virtual unit.

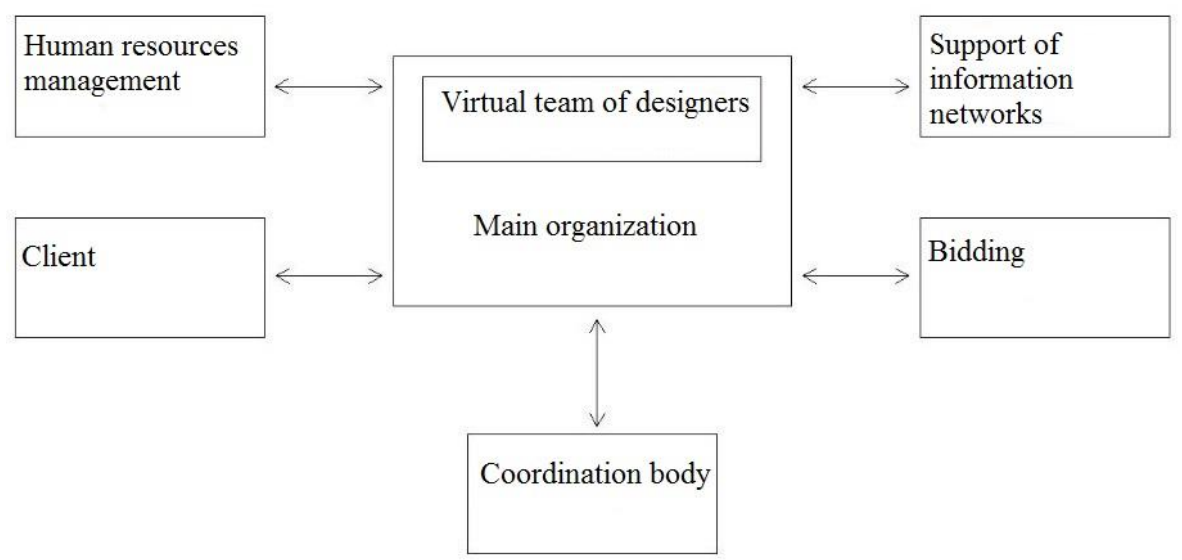

Fig. 5. Organizational structure of virtual structures. 
Based on the already presented models of virtual organization [14,15] and tasks of thesis research, we have designed a model of virtual structures of design company (fig. 6.).

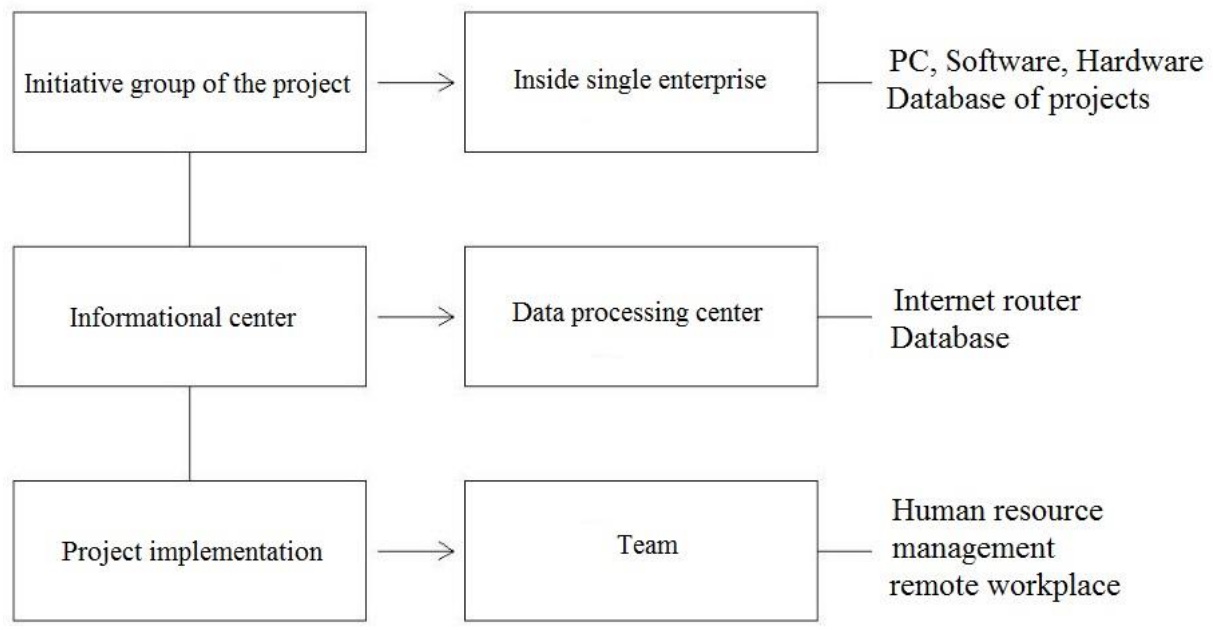

Fig. 6. Virtual structure model for design units.

\section{Conclusion}

Virtual organization can be attributed to "a team of people built on division of labor" model, which is based on the theory of human relationships and behavioral sciences. Advantages of virtual forms of organizations are possibility to select and use best resources, knowledge and skills with fewer time costs. Using the services of a virtual office, in contrast to the virtual organization, are effective when solving general work process tasks, but without any participation in construction process.

Thus, virtual organization model contains three main stages - the formation of an initiative group (team), creation of an information center and implementation of a project. The organizational structure model can be changed in accordance with the design task or other conditions. It should be noted that in any case virtual organization will have real physical structures, that is, a specific physical center.

\section{References}

1. M. Uorner, Virtual'nye organizacii (Stroyizdat, Moscow, 2005)

2. I. Mazur, V. Shapiro, Project management (Stroyizdat, Moscow, 2005)

3. M. Chuchkevich, What is a network organization? (Institut sociologii RAN, Moscow, 2012)

4. A. Slavina, Virtual and augmented reality-2016 1, 308-314 (2016)

5. S. Bolshakov, S. Sinenko, A. Slavina, Industrial and civil construction 8, 87-91 (2016)

6. S. Sinenko, A. Slavina, MATEC Web of Conference 106, 08019 (2017)

7. A. Kataev, Polytechnic University Publ. 120, 87-96 (2009)

8. M. Warner, M. Vytzel, New forms of doing business in the XXI century (Stroyizdat, Moscow, 2005)

9. S. Bolshakov, Vestnik MGSU 13, 287-294 (2013) 
10. M. Warner, M. Vytzel, Virtual organizations, new forms of doing business in the XXI century (Stroyizdat, Moscow, 2005)

11. V. Serdyuk, Management in Russia and abroad 2, 25-37 (2012)

12. V. Meitus, Control theory and practice issues 1, 28-41 (2004)

13. E. Kolesnikova, T. Kuz'mina, S. Synenko, Construction 51, 17-28 (2015)

14. V. Serdyuk, Management in Russia and abroad 2, 48-59 (2012)

15. W. Saabeel, Electronic Journal of Organizational Virtualness 4, 1 (2004)

16. A. Slavina, Construction-formation of the living environment (Stroyizdat, Moscow, 2017) 